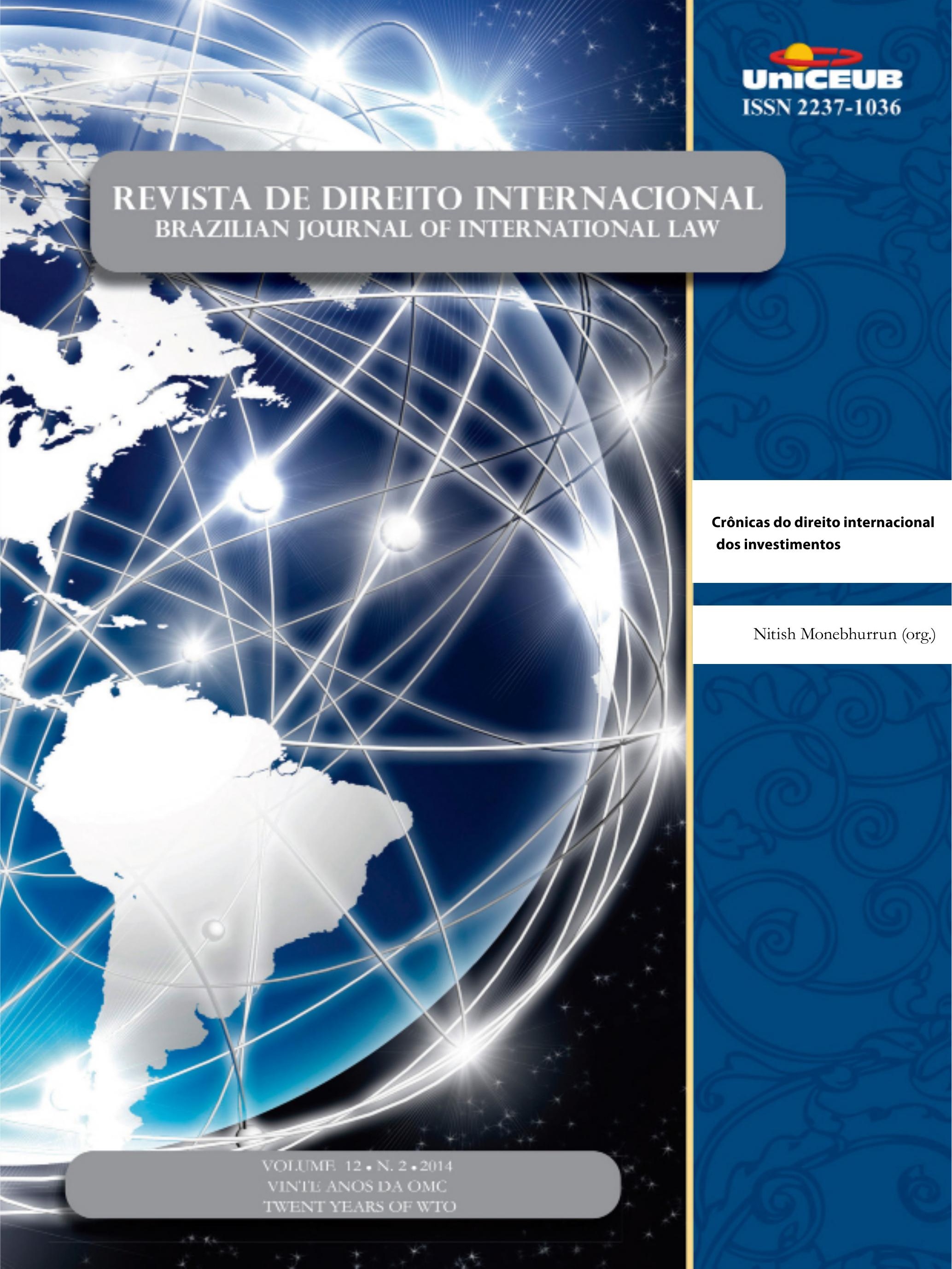


I. Crônicas

1. Crônicas da atualidade do Direito Internacional ......................................................16

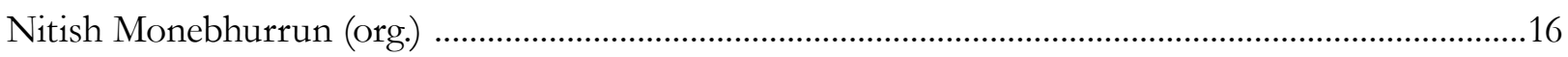

2.Decisões da Corte Internacional de Justiça e do Tribunal Internacional Sobre o Direito do Mar

Nitish Monebhurrun

José Eduardo Siqueira

3. Crônicas do direito internacional dos inVestimentos

Nitish Monebhurrun

\section{Os Vinte Anos dA OMC}

EXPORT CONTROLS AS INDUSTRIAL POLICY ON NATURAL RESOURCES: REGULATORY LIMITATIONS ON CHINA - RAW MATERIALS AND CHINA - RARE EARTHS CASES.

Gustavo Ferreira Ribeiro

O problema da espionagem econômica internacional: Seria a Organização Mundial do CoMÉRCIO O FORO ADEQUADO PARA SUA APRECIAÇÃO?

Humberto A.Vasconcelos Lima

Naiana Magrini Rodrigues Cunha

International Standards for Intellectual Property Rights Protection: a reflection on CLIMATE-FRIENDLY TECHNOLOGY TRANSFER.

Guihong Zhang

Jiani Jiang

Can Wang

Os vinte anos da OMC, suas conquistas e desafios: uma análise do Brasil e o Sistema de SoLUÇõES DE CONTROvÉRsias

Etiene M. Bosco Breviglieri

Luciano Meneguetti Pereira

A relação entre os tratados multilaterais ambientais e os acordos da OMC: é possível CONCILIAR O CONFLITO?

Fabio Costa Morosini,

Luisa Zuardi Niencheski 
Um desafio na Organização Mundial do Comércio: viabilidade de UM aCordo plurilateral SOBRE ENERGIA

Matheus Linck Bassani

CONTRATAÇõES PÚBLICAS NO ÂMBITO DA OMC: A POLÍTICA LEGISLATIVA BRASILEIRA À LUZ DO DIREITO AO DESENVOLVIMENTO

André Jansen do Nascimento

Governança global e a Organização Mundial do Comércio: desafios impostos pelo novo MANDATO DE DESENVOLVIMENTO

Letícia de Souza Daibert

Ana Luísa Soares Peres

Vinte Anos de Crise para a África? Poder, Assimetrias e a Abordagem Liberal da OMC.....239 Igor Abdalla Medina de Souza

Os MECANISMOS DE INDUÇÃo AO CUMPRIMENTO NO ÂMBITO DA OMC

Fernando Lopes Ferraz Elias

A promoção de accountability na Organização Mundial do Comércio: uma análise horiZONTAL E VERTICAL

Celso Henrique Cadete de Figueiredo

LA OMC Y EL PROCESO DE GLOBALIZACION DE LA REGULACIÓN ALIMENTARIA

Maria Eugenia Marichal

O ACORDO GATS E SUA APLICAÇÃo AOS SERVIÇOS DO COMÉRCIO ELETRÔNICO .

Gleisse Ribeiro Alves

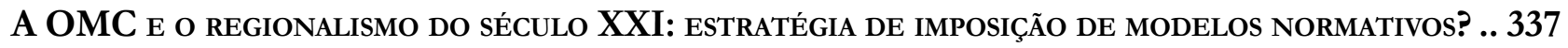
Camilla Capucio

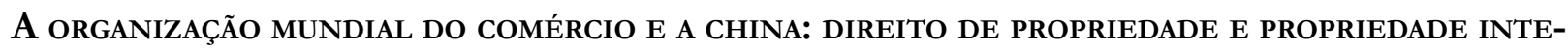
LECTUAL NO PAÍ́S

Dos contenciosos NA OMC COM ENFOQUe EM RESTRIÇões Às EXPORTAÇÕES DA CHINA 363 Marco Antônio Alcântara Nascimento 
O redimensionamento da OMC no trato dos Acordos Comerciais Regionais.

Alice Rocha da Silva

\section{Outros Temas}

Derechos Humanos en la REALIDAD ACTUAL: LA GLOBALIZACión Y El MUlTiCUlturalismo

David Falcão

IMUNIDADE DE JURISDIÇÃo dO EsTADO E REPARAÇÃo CIVIL PELA PRÁTICA DE TORTURA: O CASO ZAHRA

KAZEMI v. REPÚBLICA ISLÂMICA DO IRÃ

Patrícia Maria Lara Abreu

Rodrigo Otávio Bastos Silva Raposo

INTERREgIONAL ORgANIZATIONS (IROS) IN EUROPE: NEW SUBJECTS OF CONTEMPORARY INTERNATIONAL LAW?

Davorin Lapas

A CONEXÃo ENTRE OS DiREITOS HUMANOS E A CORRUPÇÃo

Gabriela Alves Mendes Vieira

Marcelo Dias Varella

GRUPO DE SOCIEDADES: INSTRUMENTO JURÍDICO DE ORGANIZAÇÃO DA EMPRESA PLURISSOCIETÁRIA

Daniel Amin Ferraz 


\title{
CRÔNICAS DO DIREITO INTERNACIONAL DOS INVESTIMENTOS
}

\author{
Nitish Monebhurrun*
}

\section{Tema 1: Reflexão sobre os (futuros) acordos brasileiros relativos à proteção dos investimentos: os acordos de cooperação e de facilitação de investimentos.}

\section{Introdução}

No cosmos jurídico peculiar do Direito Internacional dos Investimentos, o Brasil sempre teve uma postura sui generis: apesar de atrair muitos investimentos estrangeiros, o Estado brasileiro nunca ratificou os quatorzes tratados bilaterais ${ }^{1}$ sobreaproteçãoea promoçãodosinvestimentosporeleassinados.Estrategicamente, trata-se de uma escolha correta e pertinente. Essa postura nunca constituiu um obstáculo ao interesse dos investidores estrangeiros e tampouco ao recebimento efetivo de investimentos externos. O mercado brasileiro, a disponibilidade de recursos naturais ou humanos, a propensão à produção e à produtividade, ou a relativa estabilidade econômica, financeira e política são, entre outros, os fatores que atraem os investidores ao Brasil. A existência de tratados sobre a proteção dos investimentos poderia ser um fator a mais no caso brasileiro, porém não seria determinante. Deveras, não há uma relação direta entre esses acordos e a atração de investimentos estrangeiros. Comparado a outros países (em desenvolvimento), a postura do Brasil foi mais pragmática; o país analisou os tratados relativos aos investimentos com uma distância suficiente e inteligente para não seguir com cegueira à moda dos BITs (Bilateral Investment Treaties). Não que os BITs contenham um problema intrínseco: é apenas um meio para oferecer uma proteção jurídica aos investidores. O que pode ser criticado é a tendência que houve durante muito tempo na uniformização desses tratados: com algumas exceções e com algumas nuances, eram muito parecidos. Por exemplo, ao assinar os BITs, muitos países em desenvolvimento utilizaram apenas modelos que eles tinham com os países mais desenvolvidos. O modelo de tratado colombiano de 2007 é, nesse sentido e em muitos aspectos, uma cópia do modelo americano de 2004 (revisado em 2012). Até hoje, os interesses desses países em desenvolvimento aparecem pouco nos seus tratados. É, portanto, às vezes, um pouco burlesco quando alguns países descobrem depois (de suas celebrações) que os BITs oferecem uma proteção minuciosa aos investidores estrangeiros — conquanto poderiam tê-los negociado melhor para valorizar também os seus interesses nacionais. Outrossim, é por isso que alguns países como Equador ou Venezuela decidiram denunciar alguns de seus BITs. Essa configuração geral do regime dos BITs deve necessariamente ser considerada pelo Brasil nas negociações de seus futuros tratados.

O Brasil está atualmente negociando alguns acordos sobre a proteção dos

* Doutor em Direito Internacional Escola de Direito de Sorbonne, Paris; Professor Associado Centro Universitário de Brasília; Professor Visitante Programa de Mestrado da Universidad de la Sabana, Bogotá. nitish.monebhurrun@gmail.com investimentos com alguns de seus parceiros africanos ${ }^{2}$. Chamam-se de acordos

1 Tratados assinados com: França (1995), Holanda (1998), Cuba (1997), Portugal (1994), Chile (1994), Reino Unido (1994), Suíça (1994), Finlândia (1995), Dinamarca (1995), Itália (1995), Venezuela (1995), Corrêa (1995), Alemanha (1995), União Econômica Bélgica-Luxemburgo (1999). Todos os tratados relativos aos investimentos encontram-se no site da UNCTAD. Disponível em: $<$ http://investmentpolicyhub.unctad.org/IIA/AdvancedSearchBITResults>.

2 O autor obteve confirmação dessa informação durante um encontro com a coordenação- 
de cooperação e de facilitação de investimentos (ACFI) e tem como objetivos a gestão da governança institucional, a promoção e a proteção dos investimentos, a mitigação de riscos e a prevenção de disputas. Em si, essa (nova) decisão não é contraditória: o Estado inicialmente cético não se converteu necessariamente e repentinamente à religião dos BITs. Mais uma vez, é apenas uma decisão pragmática e estratégica. A maioria dos BITs que estão sendo negociados visam mormente à proteção dos investidores brasileiros no exterior. A conjuntura evoluiu para o Brasil, que se tornou um grande exportador de capitais e de investimentos. Estes necessitam, em alguns casos, de uma proteção jurídica nos Estados anfitriões. Implica-se, destarte, que o Estado brasileiro está se comportando como os países industrializados das décadas de 60-90, sabendo que os acordos assinados com os países africanos serão bilaterais na forma, mas unilaterais na realidade? Lembre-se, por exemplo, de que o Brasil tem mais investimentos (a proteger) em Angola que este no Brasil. Tudo dependerá do conteúdo dos tratados. É apenas o conteúdo dos futuros BITs brasileiros (2) que permitirá ao Brasil forjar uma identidade a estes, destacando-se - esperamos — do que sempre foi feito (3).

\section{Vislumbrando o conteúdo dos eventuais ACFIs brasileiros}

A negociação e a elaboração de um BIT ou de um ACFI hodierno deve necessariamente considerar a evolução do Direito internacional dos Investimentos e, para tanto, é preciso perscrutar a jurisprudência arbitral dessa área com o objetivo de conhecer todas as polêmicas e as problemáticas inerentes. Uma grande parte desse ramo do Direito Internacional foi desenvolvida pelos tribunais arbitrais: nas sentenças arbitrais encontram-se, por conseguinte, todos os conflitos, todas as contradições, todas as lacunas e todos os problemas jurídicos que devem ser entendidos e dominados antes de qualquer processo de negociação de um ACFI. O Direito Internacional dos Investimentos está mais maduro; um negociador em 2014 tem mais distância e mais técnicas para melhorar a formulação dos dispositivos mais importantes de um ACFI, se comparamos com os anos 60-90. Não seria razoável ignorar o histórico do desenvolvimento do Direito Internacional dos Investimentos durante esse

geral do Ministério do desenvolvimento, Indústria e Comércio Exterior. processo, ao risco de repetir erros que outros fizeram. Para o Brasil é uma oportunidade de considerar essa evolução ao celebrar os seus novos ACFIs. Será uma forma para antecipar qualquer futuro contencioso. Se a consideração das problemáticas clássicas da proteção dos investimentos estrangeiros consolidará, com certeza, esses acordos (A) serão, outrossim, bem-vindas considerações de interesse público — mais raras nesses tipos de acordos (B).

\section{A) Vislumbrando o conteúdo dos ACFIs brasileiros à luz das problemáticas recorrentes do Direito Internacional dos Investimentos}

Os comentários a seguir devem ser entendidos em relação ao contexto do ACFI, pois a capacidade de moldar as disposições do acordo dependerá do poder de negociação do Brasil — o que está relacionado, por sua vez, ao poder dos Estados parceiros. A capacidade de inflectir um acordo será, por exemplo, maior com a Angola que com a África do Sul, com Moçambique que com o Japão ${ }^{3}$. É com cuidado que devem ser firmados esses acordos para evitar todo arrependimento futuro como os suportados pelos países vizinhos, - como Argentina. Dessarte, utilizar um inventário dos problemas processuais, por um lado (i), e substancias (ii), por outro, facilitará a formulação dos objetivos visados em tais acordos.

(i) Moldando os ACFIs após um inventário das problemáticas processuais.

As problemáticas processuais a considerar são atinentes à própria definição dos investimentos (a) e à formulação da cláusula de resolução de controvérsias (b).

(a) Moldando a definição do conceito de investimento nos ACFIs

A definição deinvestimento éum passo fundamental, pois se trata do próprio objeto da proteção: apenas atividades caracterizadas como 'investimentos' são juridicamente protegidas. Normalmente os acordos sobre a proteção de investimentos não definem o conceito de investimento, mas propõem uma lista ilustrativa e não

3 A visita do Shinzo Abé (Primeiro-Ministro) do Japão no Brasil em agosto deste ano teve, entre outros, como objeto a negociação de acordos sobre o comércio e os investimentos (Ver: HAUBERT, Mariana. Dilma e primeiro-ministro do Japão firmam acordos bilaterais. Folha de São Paulo, São Paulo, 01 ago. 2014. Disponível em: <http://www1.folha.uol.com.br/mercado/2014/08/1494377dilma-e-primeiro-ministro-do-japao-firmam-acordos-bilaterais-parainvestimento.shtml> 
exaustiva de exemplos de investimentos ${ }^{4}$. As sentenças arbitrais elaboraram alguns critérios nesse processo de identificação de um investimento. O famoso caso Salini c. Marrocos (2001) apontou quatro critérios: uma contribuição, uma duração, um risco e uma contribuição ao desenvolvimento do país anfitrião ${ }^{5}$. Muitos tribunais utilizaram esses critérios conquanto outros se mostraram mais céticos em relação ao fator da contribuição ao desenvolvimento (Saba Fakes c. Turquia, 2010).

Com base no estado atual do direito, duas possibilidades existem ao negociar um ACFI. O primeiro é de seguir o caminho clássico e propor um projeto de acordo que contenha os mesmos exemplos de investimento que a grande maioria dos BITs. O outro implica na consideração da jurisprudência arbitral ao formular as disposições: essa jurisprudência será com certeza citada futuramente caso ocorra um contencioso envolvendo o Brasil ou um investidor brasileiro - e pode ser mais interessante antecipar algumas coisas nesse âmbito.

O elemento mais polêmico na definição dos investimentos no Direito Internacional dos Investimentos é aquele da contribuição ao desenvolvimento do Estado receptor. É possível considerar que a questão do desenvolvimento interessa todos os Estados. A definição do que constitui o seu desenvolvimento cabe a cada país. Portanto, se o Brasil quiser que os investimentos estrangeiros contribuam ao seu desenvolvimento e no mesmo sentido, se quiser participar do desenvolvimento dos parceiros (africanos), o ACFI pode ser um instrumento (humilde) para tais fins: juridicamente, é possível incluir — no corpo do

4 A título de exemplo, o BIT entre Brazil e Dinamarca (nunca ratificado) dispõe no seu artigo 1 (a): "o termo "investimento" significa todo o tipo de haveres e inclui, em particular, ainda que não exclusivamente:

i. bens tangíveis e intangíveis, móveis e imóveis e quaisquer outros direitos como concessões, hipotecas, penhoras, cauções, usufrutos, garantias e quaisquer outros direitos similares; ii. uma companhia ou empresa comercial, ou ações, títulos ou outras formas de participação em uma companhia ou empresa comercial, bem como títulos e dívidas de uma companhia ou empresa comercial; iii. rendas reinvestidas, títulos de crédito ou direitos em relação à execução de quaisquer atividades de acordo com um contrato com valor econômico; iv. direitos de propriedade intelectual, incluindo direitos autorais, patentes, marcas comerciais, tecnologia, marcas registradas, fundo de comércio, know-how e outros direitos similares; v. concessões ou outros direitos conferidos por lei ou por contrato, incluindo concessões para prospecção, cultivo, extração ou exploração de recursos naturais".

5 NITISH, Monebhurrun. A identificação dos investimentos internacionais no Direito Internacional dos Investimentos. Brazilian Journal of International Law, v. 11, n.1, p. 11-15, 2014. acordo ou em um anexo - algumas características que um investimento deve ter para ser compatível com o desenvolvimento do país anfitrião. Essas características devem ser determinadas pelos países signatários. Assim, uma atividade será qualificada de investimento e poderá se beneficiar de uma proteção jurídica pelo BIT/ACFI apenas se cumprir os requerimentos para o desenvolvimento. Será também uma forma de não deixar que um painel de árbitros decida no futuro o que é ou não uma contribuição ao desenvolvimento.

Usar esse critério implica obviamente discriminar atividades suscetíveis de receber o título de 'investimento’ e uma devida proteção em razão do seu aporte ao desenvolvimento, das outras. Alguns dirão que atuará como um limite à proteção dos investimentos, pois nem todas as atividades poderão ser protegidas. E está certo: referir-se ao critério de contribuição ao desenvolvimento significa proteger apenas as atividades favoráveis ao desenvolvimento; significaria definir o investimento em relação a sua propensão ao desenvolvimento. Tratar-se-á aqui de uma escolha dos Estados. Para tanto, o uso de peritos e especialistas do desenvolvimento pode ser útil para o entendimento técnico da relação entre investimentos e desenvolvimento - o que permitirá incluir uma paleta ampla de atividades sob a proteção do ACFI.

A este primeiro aspecto processual junta-se um outro de expressiva importância: a negociação das cláusulas de resolução de controvérsias.

(b) Moldando a cláusula de resolução de controvérsias

Duas questões devem ser examinadas aqui: o tribunal competente em casos de arbitragem internacional (b.1) e a extensão dessa competência pelo jogo da cláusula da nação mais favorecida na resolução de disputas (b.2).

(b.1) Escolher o tribunal competente em casos de arbitragem internacional

Deve ser lembrado que o Brasil não ratificou a Convenção de Washington que instituiu o Centro Internacional para a Resolução de Disputas relativas aos Investimentos (CIRDI / ICSID) em 18 de março de 1965. Mais uma vez, ao fazer o inventário do estado do direito, percebe-se que a maioria dos BITs prevê, entre outras possibilidades, a competência de tribunais constituídos sob a égide do CIRDI. Mesmo que seja uma tendência geral, não significa que essa convenção deva ser necessariamente ratificada pelo Brasil. Os investidores brasileiros podem ter acesso ao 
CIRDI sem essa ratificação. Para este propósito podem ser utilizadas as Additional Facility Rules do CIRDI cujo artigo 2 (a) permite um acesso à arbitragem aos investidores mesmo que os Estados de nacionalidade deles não tenham ratificado a Convenção de Washington. Isso pode ser previsto em um contrato ou pode ser o objeto de um compromisso de arbitragem; in fine, a decisão de admissibilidade caberá à SecretariaGeral do CIRDI. Além disso, os BITs podem prever o uso do regulamento da Comissão das Nações Unidas para o Direito Comercial Internacional (CNUDCI) em caso de controvérsias. Em todo caso, a mera ratificação da Convenção de Washington não despoja o Brasil de sua margem de manobra: a Convenção aplicar-se-á apenas se a cláusula de resolução de disputas dos ACFIs brasileiros referir-se à competência dos tribunais CIRDI. A ratificação não se equipara ao consentimento de submeter todas as disputas relativas aos investimentos aos tribunais CIRDI; o consentimento está consagrado na ratificação dos BITs que contêm a cláusula atinente a arbitragem CIRDI.

Ora, uma problemática relativa à cláusula de resolução de disputas apareceu - interessantemente —, no contencioso arbitral pelo jogo da cláusula da nação mais favorecida. Será recomendável que o Estado brasileiro cuide da formulação desta última cláusula.

(b.2) A problemática da inclusão da resolução de controvérsias no âmbito da cláusula da nação mais favorecida

Essa questão foi tratada de uma forma mais detalhada pelo presente autor nas crônicas da edição 2014.1 da mesma revista ${ }^{6}$. Em resumo, há um debate sobre a possibilidade de usar a cláusula da nação mais favorecida de um tratado assinado por um Estado para pedir o mecanismo de resolução de controvérsias previsto por outro tratado do mesmo Estado. Alguns tribunais consideraram que é juridicamente possível importar a cláusula de resolução de disputas por meio da cláusula da nação mais favorecida (Maffezini c. Espanba, 2000; Suez.c. Argentina, CIRDI, 2006; Gas Natural c. Argentina, CIRDI, 2005; Suez e Vivendi c. Argentina, CIRDI, 2006; RosInvest c. Rússia, SCC, 2010), enquanto outros mostraram-se mais céticos (Plama c. Bulgária, 2005; Salini c. Jordania, CIRDI, 2004; Berschader c. Rússia, SCC, 2006; Telenor c. Hungaria, CIRDI, 2006).

6 NITISH, Monebhurrun. O Uso da Cláusula da Nação Mais Favorecida no Direito internacional dos investimentos: de uma proteção substancial a uma proteção processual. Brazilian Journal of International Law, v. 11, n.1, p. 15-18, 2014.
O Brasil deve analisar onde se situa nesse debate, e até que ponto concorda com as duas tendências da jurisprudência arbitral. $\mathrm{Na}$ dúvida, a postura da Colômbia pode ser adotada: afirmar na própria cláusula da nação mais favorecida que esta não se estende- à resolução de disputas. O artigo IV (2) do modelo do BIT colombiano dispõe:

"The most favourable treatment to be granted in like circumstances referred to in this Agreement does not encompass mechanisms for the settlement of investment disputes [...]".

Claramente, essa decisão dependerá da outra parte signatária do ACFI. O Brasil pode ter uma postura mais liberal quando se tratar de um ACFI com um país principalmente importador de capital, pois, neste caso, o ACFI será mormente negociado para a proteção dos investidores brasileiros; haverá poucos riscos de casos contra o Estado brasileiro. Com Estados cujos investidores pretendam investir mais no Brasil (África do Sul, Japão), a formulação da cláusula da nação mais favorecida pode ser mais conservadora - excluindo a aplicação à resolução de controvérsias.

(ii) Moldando os ACFIs após um inventário das problemáticas substanciais

Situado entre o processo e os méritos, a umbrella clause (cláusula guarda-chuva) merece a atenção e a diligência do Estado brasileiro (a); será, outrossim, aconselhável considerar a evolução recente da interpretação da cláusula do tratamento justo e equitativo (b); e os limites a ser conferidos à cláusula relativa à expropriação (c).

(a) A inclusão ou não de uma umbrella clause

A cláusula, dita de guarda-chuva, permite que todas as obrigações do Estado vis-à-vis do investidor entrem no âmbito de proteção e de aplicação do $\mathrm{BIT}^{7}$. Isso significa, por exemplo, que as obrigações contratuais do Estado em relação a um determinado investimento podem ser regidas pelo BIT. Assim sendo, uma violação do contrato será internacionalizada em uma violação do BIT. Alguns tribunais arbitrais aceitaram esse princípio (por exemplo: Noble Ventures v. Romênia, 2005; Eureko v. Polônia, 2005), conquanto outros demonstram um ceticismo (por exemplo: SGS v. Pakistão, 2003).

7 A cláusula guarda-chuva do modelo do BIT da Alemanha dispõe (artigo 7.2): “ Each Contracting State shall fulfil any other obligations it may have entered into with regard to investments in its territory by investors of the other Contracting State". 
Outros ainda aceitaram a internacionalização de uma violação contratual apenas quando, sob o jus imperii, o Estado anfitrião atuou utilizando os seus poderes de polícia, as suas prérogatives de puissance publique (El Paso v. Argentina, 2006; Pan America v. Argentina, 2006).

A postura de negociação nesse caso segue a mesma lógica que a supramencionada: dependerá do outro Estado-parte ao ACFI. Muitos futuros ACFIs do Brasil terão como objeto e objetivo principal a proteção dos investidores brasileiros no exterior — sabendo já que os outros Estados signatários não mandarão tão cedo o mesmo número de investidores ao Brasil. Para esses tipos de ACFIs, a cláusula guarda-chuva oferecerá uma proteção maior aos investidores brasileiros. Malgrado, a postura pode ser mais conservadora nos BITs assinados com países que são também exportadores de capitais.

A próxima consideração substancial é atinente ao princípio do tratamento justo e equitativo.

(b) A formulação da cláusula relativa ao tratamento justo e equitativo.

Claramente, o objetivo aqui não é fazer um retrato completo desse princípio ${ }^{8}$, mas explicar uma tendência recente na sua interpretação. É sabido que o critério principal utilizado para identificar a violação da cláusula relativa ao tratamento justo e equitativo é aquele das expectativas legítimas. Uma frustração das expectativas legítimas é equiparada a uma violação da cláusula. Essa frustração ocorre, por exemplo, quando o Estado anfitrião não cumpre uma promessa explícita ou implícita feita ao investidor e na base da qual - confiando - ele se estabeleceu e começou a sua atividade. Comparando com os outros critérios do tratamento justo e equitativo ${ }^{9}$, as expectativas legítimas estão se tornando cada vez mais o critério cardinal e modelador. Três casos recentes estabeleceram que seria possível considerar as expectativas legítimas como um princípio geral de direito, segundo o artigo 38 do Estatuto da Corte Internacional de Justiça (Gold Reserve Inc. v. Venezuela, 2014; Toto Costruzioni Generali v Libano, 2012; Total v. Argentina, 2010). Essa tendência será seguramente confirmada no futuro. É indubitável que as expectativas legítimas constituem um dos princípios

8 Ver sobre esse assunto: NITISH, Monebhurrun; BARBOSA, Flávio Spaccaquerche. O Tratamento e a Proteção do Investimento Estrangeiro. Revista Brasileira de Arbitragem, ed. esp. p.107-144, set. 2011.

9 Por exemplo: a transparência, a coerência, a consistência, a estabilidade ou o devido processo legal. que oferece - e que tem oferecido - uma proteção ampla aos investidores em muitos casos.

Considerando essa evolução, não será chocante vêla expressis verbis em um BIT/ACFI — já que a linha de demarcação entre tratamento justo e equitativo e expectativas legítimas está em muitos casos muito tênue. Trata-se assim de outra possibilidade à disposição do Estado brasileiro: a redação da cláusula relativa ao tratamento justo e equitativo pode referir-se também às expectativas legítimas como sendo o seu indicador principal. Isso terá ao menos dois efeitos positivos: primeiramente, os Estados saberão sem ambiguidade o que é esperado deles e agirão de uma forma potencialmente mais diligente na sua relação com os investidores, o que é idôneo para prevenir futuros danos aos investimentos alheios; seguidamente, facilitará o trabalho hermenêutico dos tribunais. Por conseguinte, será um fulcro a mais no caminho da proteção dos investimentos, e da nitidez das normas aplicáveis para esses fins.

Dito isso, a precisão da norma pode acompanharse de sua flexibilização ${ }^{10}$ para que seja mais realista (e verdadeiramente justa e equitativa). A capacidade de oferecer tal tratamento depende em muitos casos dos recursos inatos de cada Estado. Ora, não será razoável esperar o mesmo nível de proteção de um país em desenvolvimento em comparação com um país altamente industrializado. Caso contrário, implicaria na obrigação de oferecer uma proteção absoluta ao investidor, escoimando-o de toda medida e dever de diligência - e, dessarte, infantilizando-o. Numa lógica intrínseca e em um espírito brasileiro de cooperação, especialmente com os países africanos, a cláusula sobre o tratamento justo e equitativo pode adequar a proteção esperada com os recursos dos Estados. $\mathrm{O}$ acordo sobre os investimentos de 2007 do Mercado Comum par a África do Leste e do Sul (COMESA) contém um dispositivo interessante a propósito. O artigo 14(3) do acordo dispõe:

\begin{abstract}
For greater certainty, Member States understand that different Member States have different forms of administrative, legislative and judicial systems and that Member States at different levels of development may not achieve the same standards at the same time. Paragraphs 1 and 2 of this Article do not establish a single international standard in this context.
\end{abstract}

10 Essa consideração aplica-se também à cláusula relativa à plena proteção e segurança. 
Para questões de cooperação, mas também de aperfeiçoamento do direito, será apreciável se o Brasil adotar uma formulação similar no seu ACFI. Essa mesma lógica de flexibilização pode aplicar-se à cláusula atinente à expropriação.

(c) Medindo a definição da expropriação.

Quão conturbada tornou-se hoje a questão da expropriação em razão notadamente da amplitude da definição da expropriação indireta? É uma das razões pelas quais a Alemanha é cética em relação à negociação de um Tratado Transatlântico entre os Estados Unidos e a União Europeia. Os tribunais arbitrais - e parte da jurisprudência arbitral — são acusados por alguns por esgarçar a margem de manobra do Estado e de seu poder regulador, pois, hoje me dia, muitas ações estatais equiparam-se a uma expropriação ${ }^{11}$. Exercer o poder regulador para a proteção ou a defesa dos interesses públicos pode, se o Estado se descuidar, violar os direitos protegidos dos investidores. Uma medida ambiental ou fiscal pode ser interpretada como sendo expropriatória. Essa problemática pode ser resolvida à montante, no próprio BIT/ACFI. Ao negociar o tratado e ao redigilo, é possível destacar quais atos e comportamentos do Estado não serão equiparados a uma expropriação. Nesse sentido, alguns modelos de BITs têm considerado que a regulação estatal para o interesse público - a proteção do meio ambiente, por exemplo —, não pode ser interpretada como uma expropriação indireta. $\mathrm{O}$ tratado colombiano dispõe nesse sentido:

\footnotetext{
Except in rare circumstances, such as when a measure or series of measures are so severe in the light of their purpose that they cannot be reasonably viewed as having been adopted and applied in good faith, non-discriminatory measures of a Party that are designed and appliedfor public purposes or social interest or with objectives such as public health, safety and environment protection, do not constitute indirect expropriation.
}

É um meio jurídico importante para proteger os poderes de polícia e a política interior do Estado. Formular a cláusula sobre a expropriação implica cautela: proteger os investimentos sem atravancar as prerrogativas de poder público do Estado. A confiança de ambos Estados e investidores no sistema deve ser mantida: isso é possível quando as regras são claras $a b$

11 O tema da expropriação é o objeto da segunda crônica desta edição. initio. No caso dos ACFIs brasileiros, será louvável se a proteção conferida aos investidores não ultrapassar os poderes soberanos dos Estados. É invocando questões de soberania que o Brasil nunca ratificou os BITs. Será hoje incôngruo se, para proteger os seus investidores, o Brasil propusesse um modelo de acordo - especialmente aos parceiros africanos —, que desconsiderasse o valor do poder soberano em alguns âmbitos estatais de interesse público.

\section{B) Vislumbrando o conteúdo dos ACFIs brasileiros à luz das problemáticas de interesse público.}

Os BITs / ACFIs têm como função principal a proteção dos investidores estrangeiros. Não obstante, nunca operam em um circuito fechado. Não se trata de uma coleção de normas visando apenas à proteção de interesses privados: ao menos, essa constatação decorre da evolução do Direito Internacional dos Investimentos. Para tanto, o Brasil fará um passo importante com o seu modelo de BIT se considerar questões de interesse público nos acordos (i), assim como elementos da responsabilidade social das empresas (ii).

(i) Articulando a proteção dos interesses privados com a proteção do interesse público nos BITs.

Essa colocação não é uma revolução; tampouco é anacrônica. Muitos modelos de BITs (americano, canadense, colombiano) e muitos dos novos acordos de livre-comércio (free trade agreements) já incluíram considerações ambientais, trabalhistas ou de saúde. O NAFTA de 1994 já continha tais considerações. Mais recentemente, o modelo do BIT canadense dispõe, por exemplo, no seu artigo 11:

The Parties recognize that it is inappropriate to encourage investment by relaxing domestic health, safety or environmental measures. Accordingly, a Party should not waive or otherwise derogate from, or offer to waive or otherwise derogate from, such measures as an encouragement for the establishment, acquisition, expansion or retention in its territory of an investment of an investor [...].

Numa lógica similar, os acordos de livre-comércio assinadospeloCanadá ${ }^{12}$ sãonormalmenteacompanhados de um acordo sobre a cooperação no âmbito ambiental e de outro sobre a cooperação trabalhista. Percebe-se que a referência ao desenvolvimento sustentável está

12 Ver por exemplo o acordo com Honduras que entrou em vigor em 1 de outubro de 2014. 
aparecendo cada vez mais nos acordos econômicos. É comumente admitido que a proteção dos investimentos estrangeiros não se faz em detrimento do interesse nacional. Se o Brasil deve proteger o interesse público nacional brasileiro, deve também mostrar-se disposto a ter o mesmo desempenho com os seus parceiros. Deve assegurar-se que os investimentos brasileiros não se implementem com desrespeito às considerações ambientais e sociais - mesmo que a legislação nacional dos Estados parceiros não seja tão rígida. O BIT / ACFI é o instrumento para prever e para estruturar esses aspectos dos investimentos. Deve ser traçada nitidamente nos acordos a linha de demarcação entre o poder regulador e a devida proteção ao investidor. As expectativas de ambos, Estado e investidor, devem ser protegidas para permitir um clima de confiança na cooperação econômica entre Estados por um lado, e entre Estados e investidores por outro. Por isso, não se pode negligenciar os interesses dos dois grupos. É nessa configuração que a proteção oferecida ao investidor deve ser formulada: para tanto, as negociações devem - sempre com a boa vontade e a participação séria e efetiva da parte mais influente - , apontar quais casos, fatos e atos de interesse público ${ }^{13}$ não se equiparam a uma violação do tratamento justo e equitativo, do tratamento nacional, da cláusula da nação mais favorecida, da plena proteção e segurança ou do dispositivo relativo à expropriação. Saindo novamente de uma visão apenas patológica do direito, a ideia é prevenir conflitos e disputas. Novamente a prevenção estrutura-se com regras claras definidas a montante.

Ainda nesse diálogo sobre o interesse público, outras regras podem ser coadunadas para incitar um comportamento responsável dos investidores na implementação e no exercício da sua atividade.

(ii) Considerando a responsabilidade social dos investidores na articulação entre a proteção do interesse privado e público.

Com certeza será aqui a parte mais ousada da presente crônica. Dizer que se trata de uma quebra de paradigma é um eufemismo. Isso porque invocar a responsabilidade social das empresas de uma forma séria - e jurídica — parece ser ainda um tabu. Dito isso, muitos tribunais arbitrais afirmaram que os BITs não são apólices de seguro para os investidores (Maffezzini v. Espanha, 2000; MTD Equity v. Chile, 2004); não podem prevalecer-se destes para pedir uma compensação ou

13 A definir pelos Estados. uma reparação de uma maneira absoluta - esperando que serão sempre e em todos os casos protegidos. Como supramencionados, o Direito Internacional dos Investimentos não infantiliza os investidores. Há casos nos quais o comportamento imprudente e pouco diligente do investidor foi levado em consideração pelos tribunais que não lhes acordaram a reparação requerida (Generation Ukraine v. Ucrânia, 2003; William Nagel v. República Checa, 2003; Alex Genin v. Estonia, 2001; MTD Equity v. Chile, 2004; Joseph Charles Lemire v. Ucrânia, 2011).

$\mathrm{O}$ investidor tem o dever de exercer o seu due diligence na sua relação com o Estado e deve também atuar conforme o princípio dos clean hands. O investidor que desrespeitou o direito nacional do Estado anfitrião e que investiu na desconsideração total das normas ambientais e/ou sociais não terá uma base sólida para atacar o Estado. Na configuração hodierna, na qual as empresas desenvolvem atividades cujo alcance é internacional e cuja cadeia de produção é também internacional, nessa configuração que tem revelado um desrespeito considerável das multinacionais com os princípios fundamentais do direito nacional dos países anfitriões, a questão da responsabilidade social dos investidores estrangeiros não pode mais manter-se no âmbito procrastinante da soft law.

Retirando toda ambiguidade, é preciso desde já assinalar que o BIT / ACFI não deve ter como objeto ou função a responsabilidade social das empresas. O princípio da responsabilidade social deve apenas aportar uma nuance à configuração complexa dos BITs / ACFIs. À vista disso, deve ser explicada a forma de incluir questões de responsabilidade social das empresas em um BIT / ACFI: os investidores devem, na realidade, demonstrar que merecem e podem juridicamente receber a esperada proteção do BIT / ACFI. Este deve, por conseguinte, conter alguns deveres que incumbam aos investidores: por exemplo, um dever de diligência nas esferas da corrupção, do meio ambiente, do respeito das normas trabalhistas, do respeito dos direitos humanos e das comunidades locais. Nesse sentido, o teor e a extensão da devida proteção ao investidor dependerá de como ele exerceu a sua diligência - o objetivo sendo de não (re)compensar a torpeza. Segundo o funcionamento dos mecanismos de resolução de controvérsias no Direito Internacional dos Investimentos, o Estado nunca é a parte requerente. Esse sistema pode ser mantido -, o Estado não podendo iniciar uma arbitragem contra um investidor. 
Entretanto, os elementos da responsabilidade social serão determinantes para avaliar a admissibilidade da demandadosinvestidores. Considerara responsabilidade social das empresas nos BITs / ACFIs não tem um objetivo repressivo, mas preventivo e comportamental. Auxiliará a moldar o comportamento dos investidores para que o investimento seja implementado de uma forma socialmente responsável. In fine, isto será apenas propício para consolidar a própria saúde da cooperação e do intercâmbio econômicos.

Atuando assim, o Brasil logrará forjar a sua identidade nos seus ACFIs.

3. Forjando os ACFIs com a identidade brasileira

A formulação dos BITs deixa transparecer a identidade do Estado, as suas preocupações, as suas políticas, os seus projetos, a sua integração nas relações internacionais, os seus valores. Mas, também a sua coerência. A título de exemplo, a política ambiental e social do Canadá não é apenas uma preocupação de fachada. O que se determina e o que se constrói na política interna desse país encontram-se também em espelho nas veias que sustentam as suas relações com outros Estados; o Canadá tenta agir da forma mais coerente na sua política global segundo a qual a economia é fundamental, porém não perdura sem a proteção de outros valores. Por isso, os seus BITs ou os seus acordos de livre-comércio salientam claramente a necessidade de oferecer uma proteção jurídica às relações econômicas, sem desconsiderar outros fatores sociais e ambientais.

Essa postura de coerência deve também ser apropriada pelo Brasil com o objetivo de projetar os seus valores em suas cooperações internacionais por meio dos seus futuros ACFIs. Seria realmente pouco razoável e extremamente maquiavélico se os modelos dos ACFIs brasileiros fossem apenas meras cópias dos BITs clássicos dos anos 60-90, ou seja, os mesmos que o Brasil rejeitou firmemente - e com razão. O mundo do Direito Internacional dos Investimentos - esse mundo enclausurado - está ansiosamente esperando que as cortinas se levantem para revelar o ACFI do Estado brasileiro. É para o Brasil uma oportunidade de entrar nesse mundo com identidade e originalidade, com realismo e com mensagens claras e fortes, com o objetivo de proteger os seus investidores sem negligenciar o interesse público. Considerando a sua posição e o seu peso no plano internacional, o Brasil, com toda a sua altivez, tem o dever de conduzir- se de uma forma responsável para projetar e oferecer um modelo, o seu modelo. Não se pode tornar-se uma China que, com frieza e ambições puramente materiais, decidiu colonizar o continente africano para insidiosamente dilacerá-lo.

Espera-se que o país celebre os seus ACFIs para destacar-se, talvez sem uma revolução coperniciana, porém com dispositivos novos para contribuir com a evolução do Direito Internacional dos Investimentos, para consolidá-lo - abrindo os seus horizontes para articular a proteção dos investimentos com os elementos supramencionados.

As propostas feitas nessa crônica visam regar a própria dialética dos negociadores brasileiros. São elementos de reflexão que podem ajudar a contemplar as negociações com outro olhar ou, pelo menos, com uma distância. Se é preciso cuidar da tecnicidade do Direito Internacional dos Investimentos, é justamente porque os raios de sua aplicação não se limitam apenas aos investidores internacionais.

\section{Tema 2: A desapropriação}

\section{Introdução}

As origens da desapropriação dos bens estrangeiros datam do estabelecimento dos estrangeiros - e dos seus negócios - em um território estrangeiro. A desapropriação dos bens das pessoas físicas ou jurídicas estrangeiras sempre foi um risco, um risco, aliás ligado à própria essência do investimento. Os exemplos mais recentes são as desapropriações mexicanas nos anos 20, a desapropriação (socialização) dos investimentos nos países da Europa central depois da segunda Guerra, as ondas de desapropriação decorrentes das descolonizações nos anos 60-70, e as desapropriações no Irã nos anos 80.

A desapropriação se define como uma transferência forçada da propriedade ou de um investimento privado ao Estado que se torna o novo dono do bem: implica uma transferência de propriedade, do privado ao público, tendo normalmente o interesse público como alvo. Pode haver uma desapropriação de bens e investimentos tangíveis ou intangíveis (SDMyers c. Canadá, 2000; Biloune c. Ghana, CNUDCI [1989]; CME c. República Checa, CNUDCI [2001]). A natureza da desapropriação depende da amplitude da definição do próprio investimento: se este é definido de uma 
maneira ampla, abrangente também será o âmbito da desapropriação.

Deveras, a liberalização dos fluxos dos investimentos internacionais acompanhou-se de vários casos de desapropriação, e, de uma forma paralela, do aperfeiçoamento do direito aplicável a esse problema jurídico. Hoje em dia, todos os acordos sobre a proteção dos investimentos preveem uma cláusula sobre o regime da desapropriação. Uma desapropriação é por definição legal, mas a legalidade embasa-se em condições específicas. A maioria dos casos perante os tribunais arbitrais internacionais contém uma questão relativa à desapropriação e a evolução do contencioso nesse campo sobrepujou várias formas de desapropriação, além da forma clássica. Os comportamentos do Estado e as medidas estatais são cada vez mais interpretados de uma maneira a encontrar casos de desapropriação em situações que, a primeira vista, não se equiparam a uma privação de propriedade. É a problemática da desapropriação indireta.

Para entender o regime jurídico aplicável a este fenômeno no Direito Internacional dos Investimentos, é preciso explicar as formas de desapropriação (2), o que prontificará o caminho para determinar os casos nos quais se torna possível afirmar a existência de uma desapropriação indireta (3).

\section{As formas de desapropriação}

São formas que seguem um formalismo prosaico: há desapropriações direitas por um lado (A), e indiretas, por outro (B).

\section{A) As desapropriações diretas}

Trata-se da forma clássica de desapropriação. É uma transferência de propriedade forçada e explícita: o Estado adota propositadamente uma medida (lei, decreto) para desapropriar um investimento. Há uma transferência clara da propriedade da pessoa privada à pessoa pública. Ao Estado são transferidos o usus e o abusus do investimento. Nos casos menos polêmicos, o contencioso - se houver - não é problemático, pois é apenas atinente à determinação da indenização. Uma desapropriação direita deve seguir alguns princípios: 1) um objetivo de interesse público; 2) a proporcionalidade da medida desapropriatória e; 3) uma compensação pronta, adequada e efetiva. Juridicamente, o Estado tem o direito de desapropriar ou de nacionalizar, sejam os bens nacionais ou estrangeiros: é um direito costumeiro (Topco c. Líbia, 1977). No entanto, o Estado pode limitar o seu próprio direito de desapropriar ou de nacionalizar, por exemplo, por meio contratual.

Disto isto, não é a forma de expropriação que colora principalmente o contencioso arbitral sobre os investimentos internacionais mais acostumados com o fenômeno da desapropriação indireta.

\section{B) A desapropriação indireta}

Há uma desapropriação indireta quando o Estado adota uma medida que a priori não é destinada ao investimento, mas que tem efeitos equiparados a uma desapropriação (direta). Teoricamente, o investidor mantém-se como o dono do seu investimento e da sua infra-estrutura, mas não pode mais usufruir destes, não pode mais frutificá-los. Trata-se, normalmente, de uma medida geral e impessoal — ou seja, não adotada apenas para o investidor como num caso de expropriação direta —, que visa à regulação de uma esfera específica do Estado e cuja implementação afeta drasticamente o investimento. Pode ser uma medida ambiental, uma política de revisão dos impostos ou uma política de autorização de construção. Em si, essas medidas se aplicam a todos, nacionais e estrangeiros; porém, ao ser aplicadas, os efeitos podem ser desapropriatórios — ou pelo menos, considerados como tal pelo investidor. A situação, portanto, é aquele na qual, sendo o dono da sua atividade e mantendo o abusus, o investidor não pode conduzir o seu investimento de uma maneira economicamente viável; ele perdeu o usus. Obviamente, o estudo da desapropriação indireta convida uma dose de subjetividade, pois é preciso sondar a veracidade dos efeitos desapropriatórios de uma medida atacada pelo investidor. Torna-se fundamental entender os casos e as condições que indicam a existência de uma desapropriação indireta.

\section{A existência de uma desapropriação indireta}

Uma desapropriação indireta pode ser convencional (A) ou contratual (B).

\section{A) A desapropriação indireta convencional.}

Quase todos os acordos sobre a proteção dos investimentos preveem uma proteção contra a desapropriação indireta. Embora tenha uma variedade de cláusulas sobre a questão (i), um debate existe sobre o âmbito da sua aplicação para saber, por exemplo, se a intenção do Estado importa ou se os únicos 
efeitos de uma medida bastam para determinar uma desapropriação indireta; é normalmente a teoria dos efeitos que predomina (ii) e os tribunais adotaram vários métodos e técnicas para medir o teor desses efeitos (iii).

\section{(i) As cláusulas sobre a desapropriação indireta.}

As formulações das cláusulas variam em função dos tratados; em geral, os tratados preveem um regime sobre ambas as desapropriações diretas e indiretas. $\mathrm{O}$ que foi supramencionado sobre as condições para poder desapropriar diretamente serve de base para entender os passos para concluir quanto à existência de uma desapropriação indireta. O tratado modelo dos EUA é com certeza o mais detalhado sobre as questões de expropriação e contém, por exemplo, um anexo (o Anexo B) apenas sobre essas questões. Este dispõe sobre a expropriação indireta da forma seguinte: essa forma de expropriação deve ser perscrutada caso a caso considerando os fatos próprios; um mero impacto econômico de uma medida não é automaticamente equiparado a uma expropriação; é preciso saber até que ponto o Estado interferiu nas expectativas do investidor; o caráter da ação estatal deve ser considerado; e finalmente, medidas não discriminatórias adotadas para a proteção do interesse público — como a proteção do meio ambiente, da saúde, da segurança pública não têm, em princípio um valor desapropriatório.

Os acordos normalmente não estabelecem um determinismo entre a ação estatal e a desapropriação, o que significa que os Estados têm uma margem de manobra e de apreciação razoável: uma medida não será equiparada a uma desapropriação se o Estado consegue justificar a sua utilidade e demonstrar o ser caráter não discriminatório e de utilidade pública, e se há uma compensação adequada.

Um elemento problemático ao analisar a problemática é entender se a intenção do Estado é determinante ao adotar uma medida cujos efeitos são potencialmente desapropriatórios.

\section{(ii) O predomínio da teoria dos efeitos sobre a intenção}

Em princípio, os tribunais concordam que são os efeitos de uma medida e não a intenção do Estado que a equiparam a uma desapropriação (Azurix c. Argentina, 2006). A forma da privação do investimento é menos importante que os efeitos da medida que conduz a essa privação (TECMED c. México, 2003). Aliás, essa conclusão é possível ao usar apenas os princípios de interpretação dos tratados da Convenção de Viena. Muitos tratados consideram, por exemplo, que uma desapropriação indireta é o resultado de uma medida cujo efeito - e não cuja intenção - é equiparado a uma desapropriação. Trata-se apenas dos efeitos, nitidamente explicitados nos acordos. Por conseguinte, como não há menção da intenção, não é preciso considerá-la. O tribunal de reclamação Irã-EUA já tinha afirmado esse ponto no caso Starrett Housing Corp. c. Irã (1987):

It is recognised in international law that measures taken by a State can interfere with propoerty rights to such an extent that these rights are rendered so useless that they must be deemed to have been expropriated, even though the State does not purport to have expropriated them and the legal title to the property formally remains with the original owner. (também, Tippetts c. Irã, 1984; Plama c. Bulgária, 2008).

Uma vez que aceitemos a teoria dos efeitos - sole effects doctrine -, é preciso saber como se medem esses efeitos.

\section{(iii) As técnicas para medir os efeitos de uma medida desapropriatória}

Os tribunais examinam, normalmente, a interferência do Estado na capacidade do investidor a frutificar efetivamente o seu investimento, o que não implica que deve haver uma transferência de propriedade ou qualquer outro benefício ao Estado (a); no mesmo sentido, várias medidas estatais podem cumular-se e agregar-se para resultar em uma desapropriação (b); outrossim, o princípio da frustração das expectativas legítimas do investidor é, às vezes, usado para tais fins (c).

\section{(a) A interferência no usus do investimento.}

A desapropriação indireta é também conhecida como uma expropriação de facto, eis que, não há uma privação direta de propriedade, mas uma neutralização da capacidade de fruir e de usufruir do investimento (CME c. República Checa, 2001). Uma medida estatal pode ter uma interferência incidental com o usus e, assim sendo, tornar inútil a raison d'être do investimento, a sua razão de existir, o seu propósito (Starretts $c$. 
Irã, 1983; Metalclad c. México, 2000). No caso Sporrong c. Suécia (1982), a Corte européia sobre os direitos humanos sustentou que, nesses casos, os juízes devem ir além da aparência e investigar a realidade da situação para entender até que ponto os direitos da propriedade foram efetivamente neutralizados. Não se deve considerar apenas a natureza (por exemplo ambiental, fiscal) de uma medida, mas também os seus efeitos sobre os investimentos. A situação é aquela na qual os direitos intrinsecamente inerentes a um investimento - a capacidade de produzir para obter benefícios ou rendas, por exemplo - não existem mais por causa de uma medida estatal (TECMED c. México 2003). Outros tribunais afinaram ou amplificaram o entendimento da interferência estatal e os efeitos sobre os direitos rastejados: dizem eles que as medidas contenciosas devem ter um efeito substancial que reduz ou aniquila o direito de usufruir do investimento (RFCC c. Marrocos, 2003; CMS c. Argentina, 2005; Telenor c. Hungaria, 2006). A privação dos direitos deve ser substancial. Em muitos casos, a duração dos efeitos é também útil para medir o teor da interferência no investimento. Os efeitos equiparados aos de uma expropriação devem ser de longa duração, quase permanente, no sentido que se torna quase impossível para o investidor retomar as suas atividades (Wena Hotels c. Egito, 2000; LG\&E c. Argentina, 2006; SDMyers c. Canadá, 2000). Também, o Estado não deve necessariamente beneficiar-se de algo ou se enriquecer durante uma desapropriação indireta - como num caso de desapropriação direta no qual beneficia de uma nova propriedade (Tippetts; TECMED).

Para resumir: ao demonstrar uma desapropriação indireta, o investidor deve poder provar que, embora tenha e mantenha a propriedade do investimento, ele não pode mais se beneficiar deste como qualquer investidor pode in abstracto esperar fruir da sua atividade em termos de produção e de rendimento.

Ele pode, outrossim, demonstrar a existência de uma desapropriação progressiva - creeping expropriation.

\section{(b) A existência de uma desapropriação progressiva - creeping expropriation.}

Uma desapropriação progressiva se constata quando não apenas uma medida, mas uma série de medidas têm - progressivamente, ao longo do tempo, um efeito equivalente a uma desapropriação. Medidas estatais agregadas no tempo causam, nesse caso, uma erosão dos direitos do investidor em relação a sua capacidade de fruir da sua atividade (Generation Ukraine c. Ucrânia, 2003; Siemens c. Argentina, 2007; Starretts c Irã, 1987). O investido deve demonstrar que algumas medidas reguladores do Estado se agregaram de tal forma que impediram todo uso possível e razoável da sua atividade. Nesse caso, deveras, não terá necessidade de provar a existência de uma intenção de desapropriar.

Às vezes, alguns acordos preveem que a frustração das expectativas do investidor pode ser considerada ao avaliar uma expropriação.

\section{(c) A frustração das expectativas legítimas do investidor como indicador de uma desapropriação.}

As considerações das expectativas legítimas ao lidar com a desapropriação fazem parte do direito americano e alguns consideram que esse raciocínio foi importado pelos advogados americanos no contencioso arbitral internacional. São, aliás, os acordos americanos que dispõem sobre as expectativas legítimas do investidor ao averiguar a existência de uma desapropriação indireta (mas: ver também o modelo de tratado colombiano). Não se trata da expectativa de não ser expropriado, mas de poder fruir do investimento. No caso Metalclad, o tribunal arbitral afirmou que a desapropriação de facto é um:

$$
\begin{aligned}
& \text { covert or incidental interference with the use of } \\
& \text { property which has the effect of depriving the } \\
& \text { owner, in whole or in significant part, of the use } \\
& \text { or reasonably-to-be-expected economic benefit } \\
& \text { of property even if not necessarily to the obvious } \\
& \text { benefit of the host State. }
\end{aligned}
$$

A desapropriação priva o investidor do benefício que poderia esperar: nesse caso, é preciso verificar se a privação da propriedade e do usus constituíram um obstáculo ao rendimento da atividade. Por exemplo, no caso Occidental c. Ecuador, a expropriação não foi admitida em razão de uma recusa do Estado a reembolsar a IVA ao investidor, pois, segundo o tribunal, não houve uma "deprivation of the use or reasonably expected economic benefit of the investment". No caso TECMED, o tribunal ressaltou que "the Claimant's expectation was that of a longterm investment relying on the recovery of its investment and the estimated return through the operation of the Landfill during its entire useful life".

Até certo ponto, no entanto, a relação expectativas legítimas e desapropriação pode sercriticada. No caso de uma desapropriação direta, o investidor perde o usus 
e o abusus. Ele não é mais o dono, o proprietário, e não pode mais frutificar a atividade que foi transferida ao Estado. Ao analisar um caso de desapropriação indireta, a mesma lógica dever ser seguida. Primeiramente, é claro que não se trata de uma perda do abusus, porque o investidor mantém-se como o dono da empresa. Portanto, e em segundo lugar, são os efeitos sobre o usus que devem ser comparados e eventualmente equiparados. Os benefícios - e as expectativas de benefício - são apenas as consequências do usus, e podem ser realizados ou não, dependendo da conjuntura econômica da atividade. O que reflete melhor uma desapropriação de facto é a possibilidade do investidor de continuar em condições normais e razoáveis a sua atividade: deve ser verificado se continua como mestre do seu investimento. Para isso, não é necessário verificar as rendas esperadas; a capacidade de continuar a atividade do investimento basta amplamente. Pode ser comparado à influência e ao domínio que o investidor tinha sobre a sua atividade ao investir com a situação após uma determinada medida estatal. Focalizar sobre os benefícios equipara-se a falsificar a realidade de um investimento que não sempre conduz a lucro. O risco de uma perda é inerente a qualquer atividade econômica, como um investimento (CPJI, Oscar Chinn, 1934). Decorre, consequentemente, que uma incerteza desse tipo não pode se tornar critério de uma desapropriação indireta: é mais fácil pleitear a existência de expectativas para poder usar um bem ou um investimento que a existência de expectativas para obter benefícios deste.
Além dessa forma de expropriação convencional — decorrente de um tratado —, encontra-se outra forma de desapropriação: a forma contratual.

\section{B) A desapropriação contratual}

O instrumento jurídico relevante nesse caso é um contrato de investimento entre o investidor e o Estado, e a questão é de saber se uma violação contratual equipara-se à desapropriação. Desde já, é possível afirmar que uma mera violação de um contrato pelo Estado anfitrião não é uma desapropriação, pois nesse caso haverá uma banalização do sentido real da expropriação — e do seu teor de gravidade.

Uma violação contratual será equiparada a uma desapropriação apenas quando o Estado agiu com poderes e capacidade que apenas cabem à competência de uma pessoa pública; a intervenção dele deve ser feita com o uso das prérogatives de puissances publiques formalizadas em atos de autoridade pública. Por exemplo, o não pagamento da prestação devida ao investidor, o não pagamento de uma dívida não implica desapropriação, pois fazem parte do jus gestionis e não do jus imperii (Waste Water Management c. México, 2004; SGS c. Filipinas, 2004; Bureau Veritas c. Paraguay, 2009). Portanto, apenas a adoção de decretos, leis, atos e medidas executivas no âmbito dos poderes reguladores podem violar um contrato, sobrepujando a violação ao nível de uma desapropriação. 
Para publicar na Revista de Direito Internacional, acesse o endereço eletrônico www.rdi.uniceub.br ou www.brazilianjournal.org.

Observe as normas de publicação, para facilitar e agilizar o trabalho de edição. 